\title{
The Innovative Moments Coding System and the Assimilation of Problematic Experiences Scale: A case study comparing two methods to track change in psychotherapy
}

\author{
MIGUEL M. GONÇALVES ${ }^{1}$, ISABEL CARO GABALDA ${ }^{2}$, ANTÓNIO P. RIBEIRO $^{1}$, \\ PATRÍCIA PINHEIRO ${ }^{3}$, RAQUEL BORGES ${ }^{1}$, INÊS SOUSA ${ }^{4}, \&$ WILLIAM B. STILES $^{5}$ \\ ${ }^{1}$ School of Psychology, University of Minho, Braga, Portugal; ${ }^{2}$ Department of Personality, Assessment and Psychological \\ Treatments, University of Valencia, Valencia, Spain; ${ }^{3}$ Psychology, ISMAI, Portugal; ${ }^{4}$ Mathematics and Applications, \\ University of Minho, Guimarães, Portugal \& ${ }^{5}$ Psychology, Miami University, Oxford, OH, USA
}

(Received 23 October 2012; revised 25 fune 2013; accepted 12 August 2013)

\begin{abstract}
The Assimilation of Problematic Experiences Scale (APES) and the Innovative Moments Coding System were applied to transcripts of a successful case of linguistic therapy of evaluation independently by different research groups. Assimilation theory and research suggest that higher APES scores reflect therapeutic gains, with a level of approximately 4.0 separating good from poor outcome cases. The innovative moments (IMs) model suggests that IMs classified as reconceptualization and performing change occur mainly in good outcome cases, whereas action, reflection and protest occur in both good and poor outcome cases. Passages coded as reconceptualization and performing change were rare in this case, but $100 \%$ of them were rated at or above APES 4 . By contrast, 63\% passages coded as action, reflection or protest were rated below APES 4 (Chi-square $=28.62, \mathrm{p}<.001)$. Implications for research are discussed.
\end{abstract}

Keyword: process research

The assimilation model (Stiles, 2002, 2011; Stiles et al., 1990) and the innovative moments model (Gonçalves, Matos, Santos, 2009; Gonçalves, Ribeiro, Mendes, Matos, \& Santos, 2011) offer related ways to understand and measure the process of therapeutic change. In this article we explore how the assimilation model converges and diverges with the innovative moments model, and we report the results of applying the two coding systems independently to session transcripts of one successful case of psychotherapy. In order to compare these systems we analyze each IM code to check if it coincides with APES. We begin by briefly describing the models and discussing their conceptual similarities and differences.

\section{The Innovative Moments Model}

The innovative moments model $^{1}$ has been constructed and refined through studies using the Innovative Moments Coding System (IMCS; Gonçalves et al., 2011). This model suggests that people use narratives to organize meaning (Bruner, 1990). Clients seek therapy because their lives are shaped by a self-narrative that influences how they feel, think, and behave in problematic ways (White, 2007; White \& Epston, 1990). The problematic selfnarrative ${ }^{2}$ has a pervasive influence on how relations are organized and on emotional processes, shaping how events are perceived, how they are valued, what are considered reasonable forms of actions, how the future is anticipated, and so forth. For instance, a depressive client may disregard his or her own wishes, deferring to what others feel and think. We may conceive this constraining effect as an internally imposed rule that shapes what is conceived as possible (e.g., doing what my husband wishes is the best way for me) or impossible (e.g., to feel as a valid person, with genuine feeling and thoughts). From this perspective, self-narratives and experience are both parts of a hermeneutic cycle: The way people ascribe meaning to the experience is shaped and shapes the experiences. Of course, there are times in which these components may appear dissociated, as

Correspondence concerning this article should be addressed to Miguel M. Gonçalves, School of Psychology, University of Minho, Braga, 4710 Portugal. Email: mgoncalves@psi.uminho.pt

(C) 2013 Society for Psychotherapy Research 
when clients narrate rationalizations (narration without experience) or when emotions occurs without any mediation (emotion without narrative) (see Angus \& Greenberg, 2011). When these two parts of the cycle appear broken in psychotherapy therapists usually develop efforts to bridge the gap between them.

Congruently with White and Epston's (1990) narrative therapy, the innovative moments model hypothesizes that change occurs through the emergence and expansion of novelties or innovative moments (IMs), which are exceptions to the problematic self-narrative. As IMs emerge and are amplified in the therapeutic dialogue, they may disrupt the problematic self-narrative, leading to the formation of a new, more adaptive self-narrative.

The current version of the model distinguishes five different types of IMs: action, reflection, protest, reconceptualization and performing change (see Table I).
(1) Action IMs concern behaviors that challenge the dominance of the problematic self-narrative.

(2) Reflection IMs concern the emergence of new understandings or thoughts that oppose the problematic narrative or are incongruent with the problematic self-narrative.

(3) Protest IMs may be either action or thoughts, but in either case they imply an active rejection of the problem, the assumptions behind it, or the persons that may support the problematic self-narrative.

(4) Reconceptualization IMs contain two elements: (1) a contrast between a previous problematic self-narrative and a new emergent functional one; and (2) an understanding of the process that allowed this transformation.

(5) Performing change IMs concern the anticipation or planning of new experiences, projects, or activities at the personal, professional, or

Table I. Innovative Moments grid (Version 7.2)

\begin{tabular}{lll}
\hline Types of IMs & Subtypes & Contents \\
\hline
\end{tabular}

\section{Action \\ Actions or specific behaviors against the problem(s).}

\section{Reflection}

Thinking processes that indicate the understanding of something new that creates a change in the problematic pattern (e.g., thoughts, intentions, interrogations, doubts).

\section{Protest}

Moments of critique, which involve some kind of confrontation (directed at others or versions of oneself); it could be planned or actual behaviors, thoughts, or/and feelings.

\section{Reconceptualization}

Process description, at a meta-cognitive level (the client not only manifests thoughts and behaviors outside the problematic self-narrative, but also understands the processes that are involved in it).

\section{Performing Change}

References to new aims, experiences, activities, or projects, anticipated or in action, as consequence of change. (i) Creating distance from the problem(s)

(ii) Centered on the change

(i) Criticizing the problem(s)

(ii) Emergence of new positions
New coping behaviors facing obstacles. Effective resolution of unsolved problem(s). Active exploration of solutions. Strategies implemented to overcome the problem.

Comprehension - reconsidering causes of problems and/or awareness of their effects.

New problem(s) formulations. Adaptive self-instructions and thoughts. Intention to fight problem(s) demands, references of self-worth and/or feelings of well-being.

Therapeutic process - reflecting about the therapeutic process. Change process - considering the process to overcome the problem(s); references of self-worth and/or feelings of wellbeing (as consequences of change).

New positions - references to new/emergent identity versions in the face of the problem(s).

Position of critique in relation to the problem(s) or/and the others who support it. The other could be an internalized other or facet of oneself.

Positions of assertiveness and empowerment. Repositioning oneself towards the problem(s).

Reconceptualization always involves two dimensions:

A. Description of the shift between two positions (past and present).

B. The process underlying this transformation.

Generalization to the future and other life dimensions of good outcomes.

Problematic experience as a resource for new situations. Investment in new projects as a result of the process of change. Investment in new relationships as a result of the process of change.

New skills unrelated to the problem.

Re-emergence of neglected or forgotten self-versions. 
relational level, as a consequence of the change achieved so far.

Results of nomothetic studies (Gonçalves et al., 2012; Matos, Santos, Gonçalves \& Martins, 2009; Mendes, Ribeiro, Angus, Greenberg, \& Gonçalves, 2010) and case studies (Gonçalves, Mendes, Ribeiro, Angus, \& Greenberg, 2010; Ribeiro, Gonçalves, \& Ribeiro, 2009) led Gonçalves and collaborators to suggest a model of change for brief therapy (see Figure 1). In the initial sessions the IMs that emerge are mainly action and reflection, usually with a clear dominance of reflection. These two types of IMs are signs to the self and significant others (therapist included) that novelties are emerging, characterized by new ways of acting, thinking and feeling, which challenge the previous dominant problematic self-narrative. Protest IMs typically emerge slightly later, but in some cases protest IMs too emerge at the beginning of therapy.

In the middle of therapy reconceptualization IMs emerge, and through these IMs the client achieves a position of authorship over the process of change. The client becomes not only the protagonist in his or her self-narrative but an active author as well (cf. Sarbin, 1986). To put it in another way, reconceptualization allows a metaposition from which to view the contrast between past and present, that is, between the problematic self-narrative and the emergent alternative one (see Dimaggio, Salvatore, Azzara, \& Catania, 2003, and Hermans, 2003 on the importance of a metaposition in the change process). Reconceptualization is almost absent from poor outcome cases, whereas in good outcome cases it becomes the most common form of innovation in the later stages of therapy (Gonçalves et al., 2012; Matos et al., 2009; Mendes et al., 2010). Reflection, action and protest IMs continue to occur late in therapy. To the extent that they develop the same (new) theme, they reinforce the reconceptualization IMs, creating a virtuous cycle of change (Gonçalves, Matos, et al., 2010). That is, as the person narrates him or herself differently than before (reconceptualization IMs) other IMs congruent with this theme (e.g., assertion toward others) reinforce the reconceptualization, which facilitates production of still more novelties (Ribeiro, Bento, Salgado, Stiles, \& Gonçalves, 2011).

Finally, performing change extends the emerging self-narrative into the future, making it clear to the client that the new way of making sense of the world, the self, and others has a future and can be safely developed.

\section{The Assimilation Model}

The assimilation model suggests that people's experiences leave traces, which can be reactivated and used as resources in new situations. These traces have an agentic quality and are metaphorically described as voices in the self. That is, these traces left by experiences are not passive, like a copy or a photograph of the past; instead they have a story to tell. When the voices are addressed by circumstances that are similar to the earlier experiences, they respond by speaking and acting.

Along these lines, the self is viewed as a community of such voices (Honos-Webb \& Stiles, 1998; see also Hermans \& Hermans-Konopka, 2010, on the dialogical conception of the self) and self-narratives are conceived as the result of the continuous dialogue between the multiple internal voices.

To illustrate, imagine the following situation: a person feels that his or her rights are violated and decides to assert his or her own wishes. From the perspective of the assimilation model, this situation is an activation of traces of previous analogous situations in which this voice was formed, and the assertion is a manifestation of an agentic part of the self. When this assertive voice manifests itself,

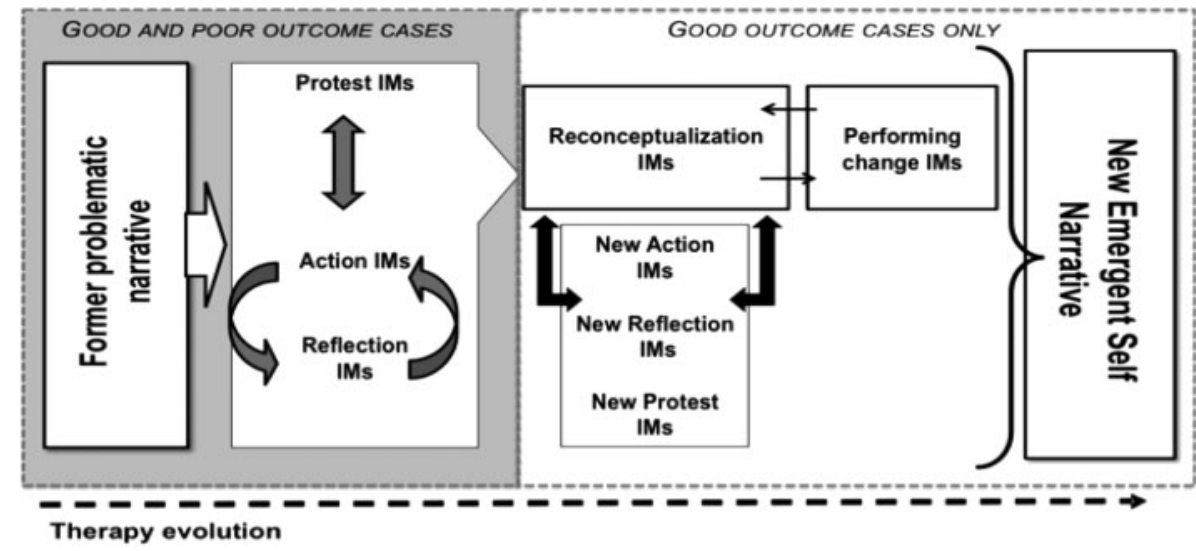

Figure 1. A heuristic model of psychotherapy change in the perspective of innovative moments. 
the other voices of the self are positioned in the background, leaving the center for this voice, which temporally dominates the self.

Ideally, the self operates as a kind of team, in which the most relevant voices are mobilized and heard whenever they are needed. However, some voices are problematic from the standpoint of the dominant community of voices (that is, the self). Such problematic voices may be silenced and dissociated from the community. This dissociation has costs. First, a resource is lost to the community. But second, if the problematic voice is addressed by circumstances it may emerge suddenly, unexpectedly, and painfully, producing symptoms.

As an illustration, Osatuke, Stiles, Barkham, Hardy and Shapiro (2011) found a common dialogical pattern in depressive clients: Submissive voices (being the self's dominant narrator) normally represent the self and organize the majority of the person's experiences. These are in conflict with - and tend to suppress - any autonomous and assertive voice. The silencing of an assertive voice has negative consequences. The person's rights are easily violated by others, and this breeds a feeling of being a less able and less respected person, increasing depressive symptomatology. The conflict between these two voices leads to emotional suffering, as the problematic assertive voice struggles to be heard and accepted. In successful therapy, the assertive voice may be assimilated, and it may become more smoothly accessible as it joins the community of voices. Assimilating the assertive voice into the self enriches the resources of the person.

Thus, therapeutic work consists in facilitating assimilation of disconnected voices by the dominant community of voices. Accommodation by both sides occurs as the voice is being assimilated by the self; both the non-dominant (problematic) voice and the community of voices are changed. As the communication between parts of the self develops, they come to share a common language, so they can understand each other. This common language is called a meaning bridge (Stiles, 2011).

The process of assimilating problematic voices into the self appears to follow a sequential order that is summarized in the eight stages of the Assimilation of Problematic Experiences Scale (APES; see Table II; Stiles, 2002; Stiles, Meshot, Anderson, \& Sloan, 1992; Stiles et al., 1991). These eight stages are organized from (0) warded off/dissociated to (7) integration/mastery, that is, from full dissociation of the voice, to a complete integration (see Table II). The APES is considered as a continuum, and intermediate ratings (e.g., 2.3, 3.6) are allowed.

Many studies have shown the applicability of APES to the analysis of the therapeutic process (see Stiles, 2002, 2011 for reviews). Progress in therapy is associated with a progression toward higher levels of APES, in which the formerly dissociated voice becomes progressively integrated. In one study, successful psychotherapy cases always attained APES level 4 (understanding/insight) or higher, whereas poor outcome cases never achieved this level (Detert, Llewelyn, Hardy, Barkham, \& Stiles, 2006). Affective patterns evolve with the eight stages (Stiles \& Brinegar, 2007; Stiles, Osatuke, Glick, \& Mackay, 2004). Stage 0 may have minimum pain, insofar as the non-dominant voice is dissociated. In stages 1, 2 and 3, affect is highly negative and the suffering is intense. After Stage 4, suffering is reduced, and the affect tends to be more positive. At stage 7 it becomes neutral again, as the assimilated voice is no longer a novelty and is now a wellintegrated (and thus unremarkable) part of the self.

It should be emphasized that the progression along the APES sequence is not linear in therapy, and setbacks are common in good outcome cases (Caro Gabalda, 2006, 2008; Caro Gabalda \& Stiles, 2013; Detert et al., 2006; Knobloch, Endres, Stiles, \& Silberschatz, 2001; Leiman \& Stiles, 2001). On the other hand, on close inspection, what appear to be setbacks usually turn out to be subtle shifts of topic. That is, for a variety of reasons, clients may shift from a more advanced strand of a problem to a less advanced strand, yielding lower APES ratings even though positive progress is being made (Caro Gabalda \& Stiles, 2013; Honos-Webb, Surko, Stiles, \& Greenberg, 1999; Stiles, 2005).

\section{Comparison of the Innovative Moments Model with the Assimilation Model}

Convergent conceptualizations of self and goals of treatment. Both models characterize the self as multifaceted, inhabited by several, sometimes contradictory internal voices that may struggle to be heard. Like Hermans and Kempen (1993), both models reject the conventional view of self as omniscient narrator, represented by a centralized position or voice. Both models further suggest that when the self restricts the diversity of voices, problems tend to occur. In the assimilation model the restriction is understood as a suppression or silencing of nondominant voices. In the innovative moments model this restriction is conceived as a confining problematic self-narrative that is unable to encompass the person's diversity of the experiences.

Both models suggest that as therapy successfully progresses, flexibility is developed, allowing previously suppressed or avoided voices to emerge (in the assimilation model) and producing innovative alternatives to the problematic self-narrative (in the 
Table II. Summary of Assimilation of Problematic Experience Scale

\begin{tabular}{|c|c|}
\hline Stages & Description \\
\hline 0 . Warded off/ & Content is unformed; client is unaware of the problem. \\
\hline Dissociated & Distress may be minimal, reflecting successful avoidance. \\
\hline $\begin{array}{l}\text { 1. Unwanted thoughts / active } \\
\text { avoidance }\end{array}$ & $\begin{array}{l}\text { Content is distressing thoughts. Client prefers not to think about it; topics are raised by therapist or } \\
\text { external circumstances. Affect is often more salient than the content and involves strong negative } \\
\text { feelings - anxiety, fear, anger, sadness. }\end{array}$ \\
\hline 2. Vague awareness / emergence & $\begin{array}{l}\text { Client acknowledges the problematic experience and describes distressing associated thoughts but } \\
\text { cannot formulate the problem clearly. Affect includes acute psychological pain or panic associated with } \\
\text { the problematic thoughts and experiences. }\end{array}$ \\
\hline $\begin{array}{l}\text { 3. Problem statement / } \\
\text { Clarification }\end{array}$ & $\begin{array}{l}\text { Content includes a clear statement of a problem - something that could be worked on. Affect is } \\
\text { negative but manageable, not panicky. }\end{array}$ \\
\hline 4. Understanding / Insight & $\begin{array}{l}\text { The problematic experience is placed into a schema, formulated, understood, with clear connective } \\
\text { links. Affect may be mixed, with some unpleasant recognitions, but also with curiosity or even pleasant } \\
\text { surprise. }\end{array}$ \\
\hline 5. Application / working through & $\begin{array}{l}\text { The understanding is used to work on a problem; there are specific problem-solving efforts. Client may } \\
\text { describe considering alternatives or systematically selecting courses of action. Affective tone is positive, } \\
\text { businesslike, optimistic. }\end{array}$ \\
\hline $\begin{array}{l}\text { 6. Resourcefulness / problem } \\
\text { solution }\end{array}$ & $\begin{array}{l}\text { Client achieves a solution for a specific problem. Affect is positive, satisfied, proud of accomplishment. } \\
\text { As the problem recedes, affect becomes more neutral. }\end{array}$ \\
\hline 7. Integration / mastery & $\begin{array}{l}\text { Client successfully uses solutions in new situations; this generalizing is largely automatic, not salient. } \\
\text { Affect is neutral (i.e., this is no longer something to get excited about). }\end{array}$ \\
\hline
\end{tabular}

Note. From Honos-Hebb, Stiles, Greenberg and Goldman (1998, p. 265).

innovative moments model). Thus, in the assimilation model, as therapy successfully progresses, a more flexible and complex self-community is developed. In the words of Honos-Webb et al. (1999) "when meaning bridges are established, dialogue and transitions among voices are smooth and comfortable, thus permitting multifaceted complexity" (p. 450). In the assimilation model, narratives are understood as a form of meaning bridges (Osatuke et al., 2004; Stiles, 2011). From the standpoint of the innovative moment model, when a problematic selfnarrative is challenged by the emergence of IMs and a new self-narrative is constructed, the flexibility increases, as the client is now more able to construe a wider variety of experiences, including those that had no place within the problematic self-narrative. Thus, in both models, as new or previously silenced voices are integrated into the self, they are allowed to tell new narratives of the self, which increases the self's flexibility.

Both models suggest that development of a metaperspective is fundamental in the process of change. In the assimilation model research suggests that level 4 (insight) is necessary for successful change in psychotherapy (Detert et al., 2006). Meaning bridges become fully articulated only after this stage. In the innovative moments model reconceptualization innovative moments are associated with successful change. Reconceptualization is a form of insight in which a meaning bridge is established between the problematic past and the changing present. From a dialogical perspective, the formation of meaning bridges can be seen as a formation of an observing position or a meta-position that manages the complexity of I-positions (Hermans, 2003; Hermans \& Hermans-Konopka, 2010).

As Osatuke et al. (2011) argued in the case of depression, when a previously silenced assertive voice is assimilated into the self, the submissive voice loses its dominance and the person is able to take more assertive positions. In the innovative moments model, the new expression by the assertive voice can be described as the emergence of IMs, whatever the form they may take (e.g., action, reflection). Moreover, the loss of dominance of the submissive voice is described as a reduction in the power of the problematic self-narrative.

Finally, based on observations from previous studies, both models propose a developmental course for change in successful psychotherapy. The assimilation model proposes that assimilation proceeds according to the APES (Table II), albeit with frequent setbacks that serve to collect varied strands of the problem together (Caro Gabalda \& Stiles, 2009, in press; Osatuke et al., 2005). The innovative moments model proposes that novelties enter and reshape the client's narrative in a predictable order, shown in Figure 1. Thus, there should be an orderly correspondence between successive APES stages and successive types of IMs. Our study sought to assess this expectation.

\section{Design and Hypotheses}

The purpose of our study was to understand whether and how the APES and the IMCS converge. To advance this purpose, we compared the results of independent scoring of transcripts of a successful 
psychotherapy case using the APES and ICMS. Given the developmental sequences of change proposed by these two models (see Table II and Figure 1 ), we expected that relatively lower APES stages should be associated with action, reflection, and protest IMs, whereas higher APES stages should be associated with reconceptualization and performing change IMs. Based on the previous research (Detert et al., 2006; Stiles, 2006), we split the APES at stage 4 (cf. Table II). Specifically, then, our main hypothesis was that APES scores below 4 would tend to be associated with action, reflection, and protest IMs, whereas APES at or above 4 would tend to be associated with reconceptualization and performing change IMs.

\section{Method}

\section{Client}

María (a pseudonym), 54 years old, was treated with linguistic therapy of evaluation (LTE) for 14 sessions during a 4 month period. Therapy was conducted in Spanish, the first language of María and the therapist. She was a successful case obtained from a sample that studied the efficacy of LTE (Caro Gabalda, 1992, 1996). Analyses of this case from an assimilation model perspective have been described elsewhere (Caro Gabalda, 2006, 2007, 2008, 2009).

María received her treatment in the Psychiatric Unit in one of the main hospitals in Valencia, Spain, and was treated by Isabel Caro Gabalda, a trained cognitive therapist and the founder of LTE. She was referred for psychological treatment by her psychiatrist and was diagnosed as having a generalized anxiety disorder. Her main concerns and ruminations were about her bodily symptoms (dizziness, tiredness, vertigo, etc.) and their consequences, mainly her inability to perform daily chores, need for sick leave, and so forth. She also had some depressive symptoms, such as despair and sadness. Her pre- and post-test scores on standard measures are shown in Table III.

María's 14 sessions were transcribed verbatim using an adaptation of the procedure described by Mergenthaler and Stinson (1992). The transcribed text included a total of 130,606 words, or an average of 9329 words per session.

\section{Treatment}

LTE is based on Korzybski's (1933, 1951) general semantics theory. LTE centers on the concept of evaluation, which encompasses thinking and feeling and seeks linguistic change by using linguistic
Table III. Pre-test, post-test and follow-up scores (one year after post-test) from María

\begin{tabular}{lccc}
\hline Questionnaires & Pre-test & Post-test & Follow-up \\
\hline HAD-Anxiety & 10 & 4 & 0 \\
HAD-Depression & 3 & 1 & 1 \\
BDI & 20 & 2 & 3 \\
STAI-S & 36 & 10 & 10 \\
STAI-T & 42 & 14 & 10 \\
\hline
\end{tabular}

Note. HAD = Hospital Anxiety and Depression Scale from Zigmond and Snaith (1983) (0-4: free of symtoms; 5-9: doubtful case; 10-21: symptoms of anxiety and depression; BDI = Beck's Depression Inventory (19-25: mild depression) (Beck, Ward, Mendelson, Mock, \& Erbaugh, 1961); STAI = State and Trait Anxiety Inventory from Spielberger, Gorsuch and Lushene (1970) (State anxiety mean: 23.30; Trait anxiety mean: 24.99).

techniques. It has been developed to treat clients with emotional problems, such as anxiety and depression, has shown its effectiveness (Caro Gabalda, 1992, 1997) and has also been studied from a process research perspective to assess the operations involved in the main LTE techniques (Caro Gabalda, 1999).

The central tenet of LTE (and of general semantics) is that human beings construe the worlds of facts and their experiences through the use of language. Two main orientations towards language have been distinguished: intensional and extensional. An intensional orientation is shown by use of absolutistic language (intensionalizations such as "I must know what is happening to me and solve it," as in María's case), identifications of words as facts, mainly through labels (i.e., "I am a burden to my family," as in María's case), anticipations or putting words before facts ("If I leave home I will feel dizzy," as in María's case), and rejections and non-acceptance of facts ("I must not be so tired," as in María's case). The aim of the therapy is to promote an extensional orientation to the world of facts and experiences, described as an orientation toward lower levels of knowing, shown by extensionalizations (a conditional language, such as "I think that my tiredness depends on all the efforts I am making; I should do only the tasks I can," as in María's case), nonidentifications (as when María stopped labeling herself as a "burden," understanding that she was doing quite a lot of things), nonanticipations (as when María felt dizzy and she decided to consult first with the doctor and not to think about the causes or what it could mean), and acceptance of facts (as when María accepted that she felt tired and that she was unable to get rid of this feeling).

At the time the therapy was done, the therapist was unaware of the assimilation or innovative 
moments models. Thus, the therapy was not dictated by those models but by the principles of LTE.

\section{APES Raters and IMCS Coders}

The APES rating and IMCS coding were done independently by different research teams who lived in different countries. The APES raters included four doctoral students and two undergraduate students in their fourth year at university as well as the main researcher (one of this paper's authors). The main APES researcher developed LTE and had been doing APES studies for two years. The IMs were coded by two master's students in clinical psychology. They were trained in IMCS coding by the authors of the coding system (see below the training procedure).

The transcripts were rated according to the APES in 2004 and coded according to the IMCS in 2009. The coders who worked with the IMCS were unaware of the previous APES results.

\section{Measures}

The assimilation levels were identified using the APES (Table II; Stiles, 2002; Stiles et al., 1990, 1991), and the IMs were identified using the IMCS (Table I; Gonçalves et al., 2011).

APES rating procedure. The procedure for data preparation and APES rating was based on those used in previous assimilation studies (e.g., HonosWebb et al., 1999; Knobloch et al., 2001; Stiles et al., 1991, 1992).

Rater training. The six APES raters were trained by the main APES researcher. Raters read and discussed journal articles and previous rating manuals describing the APES and completed practice transcripts (see Caro Gabalda, 2006, 2007, 2008). The training lasted 1.5 months.

Selection of passages and identification of problematic voices. The unit of analysis for the APES ratings was the passage. A passage is a stretch of discourse. It is a flexible rating unit delimited by topic changes if these were apparent, but were otherwise arbitrary (see Stiles et al., 1991). Each passage may be characterized by the attitude ("I feel bad when I think...") expressed by the client towards an object (“... about my husband's behavior”) (Stiles et al., 1991, 1992).

The main APES researcher first read the transcripts carefully, making a catalogue of the topic (attitude and object) of each passage. To select problems on which progress was made, passages showing new understanding, or insight, were selected by the main researcher (because these are salient, easily identified moments and because problems are characteristically formulated clearly and succinctly at this stage), and the relevant attitudes and objects were then tracked forward and backward through the session transcripts to identify relevant passages, which were excerpted. Raters reviewed and agreed about the passages selected and excerpted; they were instructed, during the procedure, to look for "attitude toward an object" in order to review the main researcher's catalogue. Finally a consensual catalogue was used for locating relevant text and applying the APES by the research group. The 548 excerpted passages included $23.3 \%$ of the 130,606 total words in the transcripts of María's 14 sessions.

This procedure yielded three topics for analysis, that is, three problematic experiences about which María achieved an insight, or, using the voice metaphor, three problematic voices that came to an understanding with the dominant community:

(1) Feeling dizzy: dizziness, unsteady sensations, ear sensations, vertigo, etc.

(2) Feeling tired: ongoing body tiredness.

(3) Being unable to do things: to work, to bring money home, take care of her family according to her standards, etc.

For each of these problems, María's dominant and non-dominant (problematic) voices were distinguished, and characterizations were agreed by the raters. María's dominant voices were all related to the need for control. She needed to control and be able to take action toward overcoming problems and being fully responsible. Thus, initially her dominant voices were opposed to and tended to avoid her feelings of dizziness and tiredness and her inability to take positive corrective action (Caro Gabalda, 2009).

Assignment of APES ratings. The final step was to apply the APES (see Table II), following previously used rating manuals (Honos-Webb, Surko \& Stiles, 1998; Lani et al., 2002). The raters and the main researcher worked separately. The main researcher rated all three topics. Two of the six raters were randomly assigned to each of the three topics and were given 2 months to analyze the topic that was allocated to them.

After that, the APES ratings of the main researcher and of the raters were reviewed and compared. A first comparison, calculated using percentages, yielded agreement that varied from $43 \%$ to $59 \%$ across the three problematic voices. The group had several meetings reviewing their agreements and 
disagreements. As a result of these meetings, the main researcher and the raters each changed $20 \%$ $28 \%$ of their ratings, yielding a final agreement of $71 \%-79 \%$ (see Table IV). In subsequent comparisons, $100 \%$ of the passages were used, but in cases of disagreement $(21 \%-29 \%$ of ratings $)$ the main researcher's rating was used.

\section{IMCS coding procedure}

Coder training. During the training period, IMCS coders had weekly meetings with the authors of the manual and members of the research team being trained for other projects. Between meetings, they coded practice transcripts. The process of training included reviewing the manual with the authors, coding sample transcripts drawn from data collected for several projects, and discussing disagreements and misunderstandings until a consensus on each passage was established among all participating coders. At the end of the training period, an inter-judge reliability between this project's two coders met a criterion of Cohen's Kappa higher than .80 , based on their coding of the IMs in a set of selected excerpts of dialogues of therapeutic sessions.

Two coders worked on coding the sessions from this case. One coder coded all 14 sessions, while the second coder coded six sessions (two from the initial phase, two from the middle phase, and two from the final phase of the treatment).

Description of problematic self-narrative. IMCS coders first carefully read the whole session's transcripts. The transcripts were in Spanish, but the Portuguese coders had no difficulty reading Spanish (the written languages are very similar). They consensually defined the problematic self-narrative in this case. The problems were described in words close to the client's discourse, thus facilitating identification of the IMs in relation to it. Although they were unaware of the APES ratings, the coders

Table IV. Total number of passages associated with each problem and percentages of agreement between the raters and the main researcher

\begin{tabular}{lccc}
\hline Index & $\begin{array}{c}\text { Feeling dizzy } \\
(n=216)\end{array}$ & $\begin{array}{c}\text { Being unable } \\
\text { to do things } \\
(n=168)\end{array}$ & $\begin{array}{c}\text { Feeling tired } \\
(n=164)\end{array}$ \\
\hline $\begin{array}{l}\text { Initial agreement } \\
\text { Agreement after } \\
\text { adjustment }\end{array}$ & $54.9 \%$ & $43.5 \%$ & $59.2 \%$ \\
\hline
\end{tabular}

Note. Initial agreement $=$ percent of passages on which that raters and main researcher agreed at the first review. Agreement after adjustment $=$ percent agreement between raters and main researcher after the main researcher ratings were modified following several reviews. identified three interrelated aspects of María's problematic self-narrative which were akin to APES problematic experiences: dizziness, tiredness, and feeling unable or burdened. Coders considered ruminations about body symptoms (dizziness, tiredness) and their consequences (mainly inability to perform daily chores), as well as a need for control, as common to all three of these identified aspects of the problematic self-narrative.

Theoretically, the process of change is co-constructed between the client and therapist, so the unit of analysis may contain both client and therapist taking turns (Angus, Levitt, \& Hardtke, 1999). Therefore, the IMs could be initiated by questions or tasks suggested by the therapist, but they were coded as IMs only if the client elaborated on them.

Selection of text for coding and assignment of IMCS codes. The unit of analysis for IMCS coding was the thought unit. Coders identified first IMs and then delineated the though unit that contained them. Each identified IM was classified into one of the five mutually exclusive categories (see Table I). Sessions were coded in their original temporal order following a three-step process: (1) identification of whether an IM was present or absent, (2) if present, what type it was, and finally (3) the exact beginning and the end of that IM in the transcript. The 505 IMs identified comprised a total of $24.2 \%$ of the 130,606 total words in the transcripts of María's 14 sessions.

The inter-judge percentage of agreement was $94 \%$. This means that there was an overlapping of the thought units between both coders in $94 \%$ of the transcripts of the six sessions coded by both coders. As a measure of the agreement regarding the specific type of IM, we used Cohen's Kappa, which in this case was .92, showing a strong agreement between judges. Given this strong agreement, in this study we used the coding from the first coder.

\section{Procedure for Assessing Convergence of Systems}

Each coding system used its own unit of analysis as exposed above, as each research group independently performed the analysis in different moments in time. We compared the units, which were coded either by the IMCS or by APES. Although we could not change the different segmenting, in this paper we analysed convergence, which refers precisely to segments that were coded by both APES and IMCS.

To assess convergence, we first had to select segments of text that were scored by both systems (we use the term segment to describe the common units that were both APES passages and IMCS thought units). Because APES passages and IMCS 
thought units were decided by different procedures, this required an arbitrary rule about which ones corresponded. For our comparison, we decided that an APES passage and an IMCS thought unit would be considered as the same segment if they overlapped by at least one sentence of text (including one-word sentences). A substantial number of IMCS thought units encompassed more than one APES passage. In these cases, we collapsed the APES passages into one segment and used the highest of the constituent APES ratings. Only 11 APES passages included more than one IM thought unit. In these instances, we considered each thought unit as a separate segment. As a result, nine APES codes were counted twice, and two APES codes were counted three times. These adjustments reduced the number of APES codes from 548 to 431 in our subsequent comparisons between systems. Out of the 431 APES passages and 505 IMCS thought units, there were 216 segments of the text that were scored in both systems (i.e., that overlapped by at least one sentence).

For comparing the scores, we divided the APES ratings and the IMCS codes into high and low categories, based on the theoretical expectations explained earlier (we use the term score to encompass both APES ratings and IMCS codes). Thus, high APES ratings included scores of 4 or higher, whereas low APES ratings included scores of less than 4 . High IMCS included reconceptualization and performing change IMs, whereas low IMCS codes included action, reflection and protest IMs.

\section{Results}

\section{María's Progress in Assimilation Terms}

As reported previously, María made substantial APES progress on all three problematic experiences, "dizziness" (Caro Gabalda, 2006), "feeling unable" (Caro Gabalda, 2007) and "tiredness" (Caro Gabalda, 2008). Figure 2 shows the evolution of APES ratings across treatment, divided into low and high APES ( $<4$ and $\geq 4$ ). High-level APES ratings showed a clear tendency to increase in the later sessions.

\section{María's Progress in Innovative Moments Terms}

María also made progress in IMCS terms. Figure 3 shows the evolution of IMs across treatment, divided in the two main categories: low-level IMs (the sum of action, reflection and protest IMs) and high-level IMs (the sum of reconceptualization and performing change IMs). The 505 IMs were distributed as follows: Reflection $(79.40 \%)$ was most common.

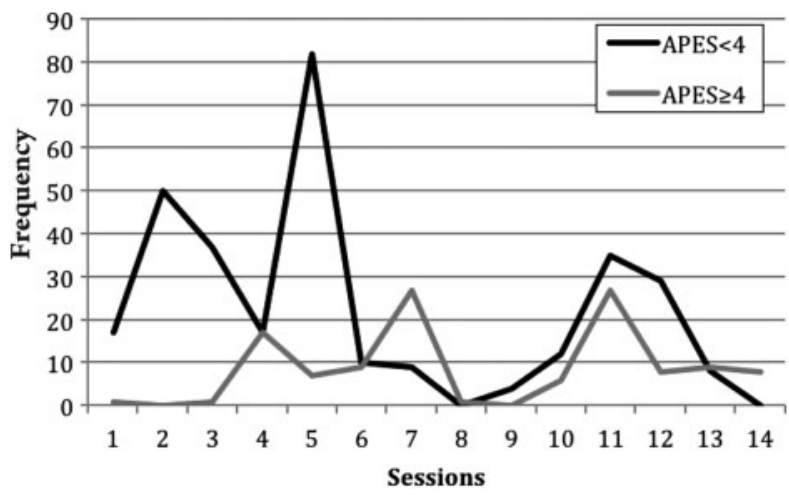

Figure 2. APES evolution. Frequencies of low-level $(<4)$ and high-level $(\geq 4)$ APES ratings in each session.

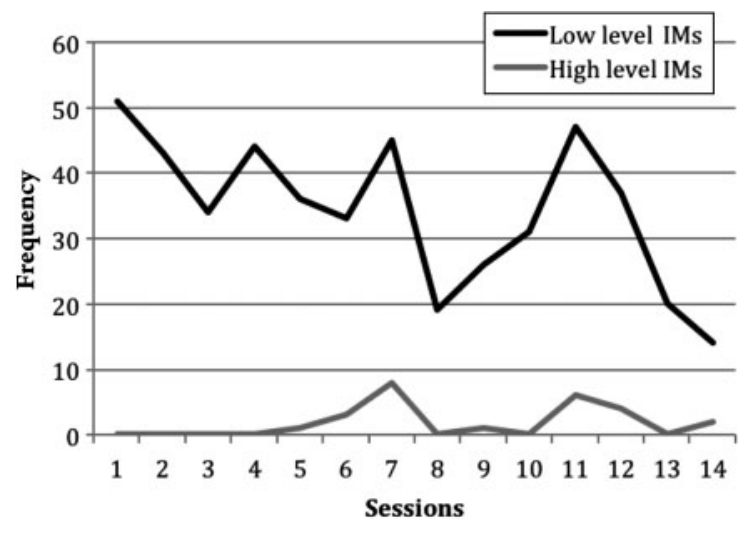

Figure 3. IMCS evolution. Frequencies of low-level (action, reflection and protest) and high-level (reconceptualization and performing change) IMCS codes in each session.

Action $(6.93 \%)$, protest $(8.71 \%)$, reconceptualization $(1.78 \%)$ and performing change $(3.17 \%)$ had a more modest presence in the treatment. The low percentage of reconceptualization and performing change is rather atypical in successful cases, although these IMs increased somewhat towards the end.

\section{Comparison of APES and IMCS Scores}

Our comparison of scores for the 216 segments scored in both systems showed significant convergence of APES ratings with IMCS codes. Table V shows the co-occurrence of low and high APES ratings ( $<4$ and $\geq 4$, respectively) with low and high IMCS codes. Segments coded as high-level IMs were relatively rare in María's transcripts, but 100\% of them were rated at or above APES 4. In the same vein, 125 out of 197 segments coded as action, reflection or protest on the IMCS were rated below APES 4 (Chi-square $=28.62, p<.001$ ).

Tables VI and VII shows the pattern in which the two systems selected session text as relevant for scoring. These tables show that segments given 
Table V. Contingencies of low and high APES ratings with low and high IMCS codes in 216 text segments scored in both systems

\begin{tabular}{lcc}
\hline Scoring criteria & APES $<4$ & APES $\geq 4$ \\
\hline Low IMs (ARP) & 125 & 72 \\
High IMs (RCPC) & 0 & 19
\end{tabular}

Chi square $=28.62, d f=1, p<.0001$.

Note. APES $=$ Assimilation of Problematic Experiences Scale; IMCS = Innovative Moments Coding System; Low (ARP) IMs $=$ action, reflection, and protest innovative moments; High (RCPC) IMs = reconceptualization and performing change innovative moments.

Table VI. Passages of APES coded on APES only and in both systems

\begin{tabular}{lccc}
\hline Explore focus of APES system & $\begin{array}{c}\text { APES } \\
<4\end{array}$ & $\begin{array}{c}\text { APES } \\
\geq 4\end{array}$ & Totals \\
\hline Passages coded by both systems & 125 & 91 & 216 \\
Passages coded by APES only & 184 & 31 & 215 \\
Totals & 309 & 122 & 431 \\
\hline
\end{tabular}

Chi square $=40.77, d f=1, p<.0001$.

Note. APES = Assimilation of Problematic Experiences Scale; IMCS = Innovative Moments Coding System.

Table VII. Passages of IMs coded on IMCS only and in both systems

\begin{tabular}{|c|c|c|c|}
\hline Explore focus of IMCS system & $\begin{array}{l}\text { Low } \\
\text { (ARP) } \\
\text { IMs }\end{array}$ & $\begin{array}{c}\text { High } \\
\text { (RCPC) } \\
\text { IMs }\end{array}$ & Totals \\
\hline Thought units coded by both systems & 197 & 19 & 216 \\
\hline Thought units coded by IMCS only & 283 & 6 & 287 \\
\hline Totals & 480 & 25 & 505 \\
\hline
\end{tabular}

Chi square $=11.86, d f=1, p=.0001$.

Note. Low (ARP) IMs = action, reflection, and protest innovative moments; High (RCPC) IMs = reconceptualization and performing change innovative moments.

high-level scores were disproportionately likely to be scored in both systems. Segments given low-level scores in either system were less likely to be selected as relevant by the other.

Appendix I compares undichotomized ratings on the two systems to show more detail on how the two systems relate and Appendix II includes examples of convergence in high levels and divergence in low levels to better illustrate the theoretical convergence and divergence between the two systems as well as the implications of our results.

\section{Discussion}

The association of high-level APES ( $\geq$ stage 4) with high-level IMs (reconceptualization and performing change) shown in Table $\mathrm{V}$ supports the suggestion that the assimilation and innovative moments models offer partially convergent conceptualizations and measurements of change. Conceptually, the high-level categories in the APES (exploring a new understanding, integration of a previously disconnected voice, application of the new perspective to problems of daily living, and the conversion of problematic experiences into psychological resources) and IMCS (reconceptualization and performing change) both imply development of a meta-perspective or metaposition. This meta-position is capable of communicating openly and effectively with other positions, having a function of management and coordination (Gonçalves \& Ribeiro, 2012). The suggestions about the importance of the meta-position are congruent with other dialogical scholars' proposals. For example, Hermans (2003) has suggested that an observer position which manages the repertoire of positions is a necessary condition for successful psychotherapeutic change. This same process has been repeatedly researched by Dimaggio and colleagues (Dimaggio \& Lysaker, 2010), regarding meta-cognitive processes in therapy. Meta-cognition is a set of abilities, involving the capability to understand one's own (and others') emotional and cognitive processes and change them, which are stimulated in the psychotherapeutic process.

María spent most of her time in therapy working at lower levels, but when she reached the higher levels, mainly late in her therapy, the systems convergently detected it (Table V).

We think that some features of our results may reflect specific characteristics of this case. The low frequency of performing change in María's therapy (relative to previously studied successful cases) could, tentatively, be explained by the agreement between María and her therapist to end therapy after 14 sessions, as soon as she had dealt with her symptoms - accepting or being able to change them. Perhaps a longer therapy would have shown higher performing change levels. Or, perhaps the low frequency of reconceptualization IMs reflects the strong emphasis on physical symptoms (e.g. dizziness, tiredness); María's changes were more centered on these symptoms and how she construed and labelled them (from an intensional toward an extensional orientation; Caro Gabalda, 1997), than on the self-narratives that organized her identity.

Because the APES and IMCS used different methods and criteria to select segments for scoring, it is not surprising that many segments identified by each system were not scored by the other system. Indeed, the overlap of 216 segments out of 431 APES passages $(50.1 \%)$ and 505 IMCS thought units $(42.9 \%)$ may be considered as large in comparison with what could be considered chance expectation that only about $5.6 \%$ of the text would be coded by both systems (based on $23.3 \%$ of the 
full text being included in APES passages and 24.2\% in IMCS thought units). The relatively high overlap may suggest that both systems attend to similar sorts of psychologically important discourse.

The pattern of overlap depicted in Tables VI and VII suggests that divergences occur more often in segments scored as low-level APES or low-level IMs. Passages rated as APES lower than 4 were less likely to be selected as containing IMs relevant to the identified themes than were passages rated at or above APES 4. Conversely, thought units coded as action, reflection, or protest IMs were less likely to be selected as relevant to Maria's three identified problematic experiences for APES rating than were though units coded at higher-level IMs. Thus, the systems appear to have more in common at higher levels of therapeutic development than at lower levels. Or perhaps relevant material is more difficult to identify when it is at lower levels of therapeutic development.

Alternatively, the greater divergence in selection of relevant material at lower levels of therapeutic development could reflect the two models' different perspectives on the early stages of change. The assimilation model depicts change beginning with the gradual emergence of a problematic experience that is rejected or generates negative affect (HonosWebb \& Stiles, 1998; Stiles et al., 1990, 1991). Each APES stage represents a small step toward change and thus progress in assimilation. The low-level IMs not selected for APES rating may be those in which the client reports feeling better or desiring to feel better without an apparent intrusion of problematic voices. Such events might be considered as reflection IMs, which may involve no change in the status of the voices. These were very common in the case of María. On the other hand, the IM model depicts change as occurring in exceptional moments that oppose the currently problematic self-narrative (Gonçalves et al., 2009). Thus, the IMCS selection procedures may ignore material at low APES levels because it is considered as problematic self-narrative rather than innovation.

Our results thus suggest that APES and IMCS are complementary and informative to each other rather than completely overlapping. The IMCS may disregard instances in which a non-dominant voice emerges along with negative affect (which is characteristic of APES levels 1 to 3). These instances can be viewed as a pre-IMs stage of the change process. The APES may disregard instances in which the client expresses well-being without any clear markers of voices in the dialogue.

The coincidence of high-level APES with high-level IMs supports both models' accounts of change late in psychotherapy (Gonçalves et al., 2009; Stiles, 2011). The higher-level IMs are clearly related to later states of assimilation of problematic voices in the assimilation model, articulation, elaboration, and consolidation of a meaning bridge. Reconceptualization IMs explicitly involve articulating and elaborating a meaning bridge between past and present self, while performing change IMs are described in much the same way as the application phase of APES (stage 5).

From the perspective of the IM model, María's therapy showed signs of only moderate success, with low levels of reconceptualization and performing change IMs. However, from the point of view of the assimilation model, María reached high levels of assimilation. The change in symptoms measured by standard pre-post symptom intensity measures supports the idea that this case was a successful one. Thus, in this case, the assimilation model's indicators converged more with the usual indexes of outcome than did the innovative moments model's indicators. This could reflect the fact that María's problems involved relatively concrete physical symptoms and the success reflected mainly accepting physical limitations and learning how to live and cope with them (Caro Gabalda, 2006, 2007, 2008). In LTE terms María's change was related to a different construction of her experiences through a different usage of language (Caro Gabalda, 1997). María's outcome may not have involved the sort of deep change in the self-narrative addressed in the IM system.

\section{Limitations and Future Directions}

Only by studying more cases will we learn whether the pattern obtained here is a typical one or specific to this case. It would be interesting to study cases that were more clearly successful from the perspective of both systems. Additionally, studying unsuccessful cases from the perspective of both systems could shed further light on the systems' convergence and divergence. Moreover, it would be interesting to agree previously on selection of passages and thought units and proceed to apply IMs and APES to the same sample of data. That will be especially relevant for analysing passages that show a change from both perspectives

Methodologically, the differences in text selection were informative, but it also interfered with clean comparisons of the scoring itself. We are aware that to use a one-sentence overlap as a proxy for it being the same segment coded by both systems introduces a potential error. Furthermore, to use the higher APES rating when the segment runs through two passages further inflates the possibility of the error. However, any criteria used to deal with the fact that each coding system used its own unit of analysis would be arbitrary. In the future, it would be interesting to agree on a common set of segments 
(passages and thought units) and thus apply IMs and APES to the same sample of text. In addition, the double and triple use of APES coding violates the independence of observations for statistical tests, but these instances were very rare: only 11 out of 216 .

Moreover, breaking the systems into high and low categories is pretty rudimentary, but with $N=1$ we would have trouble with statistical analysis of finer gradations. Anyway, this is a first comparison between these systems that suggests that both systems have similarities (mainly at the high level), but also important differences, when the lower level is considered. In the future, new studies may be developed to check and compare the full range of codes.

Future work might focus on particular phases of change. For example, researchers could study the APES 4 (Insight) stage, at which the meaning bridge is often particularly clear and well-articulated (Stiles \& Brinegar, 2007) to assess similarities and differences with reflection and reconceptualization IMs. Future work should also include the role of the therapists in a deep analysis of therapeutic tasks (see Goldsmith, Mosher, Stiles \& Greenberg, 2008; Mosher \& Stiles, 2009; Ribeiro, Ribeiro, Gonçalves, Horvath \& Stiles, 2013).

Finally, as we portray both assimilation and IMs markers as a process of change (per se) with behavioral, cognitive and emotional implications, and not only as a micro-outcome, it would be important to move from correlational studies (comparing good with poor outcome cases) to analyzing whether assimilation and IMs predict symptom changes, self-narrative changes (e.g., differences in autobiographical narrations from the beginning to the end of therapy), or both.

\section{Notes}

${ }^{1}$ The concept of innovative moment is an empirical application of the unique outcome concept from White and Epston (1990).

2 The word problematic is used differently in the two models. In the innovative moments model, the problematic self-narrative is problematic from the perspective of the therapist or the theory, insofar as it excludes important experiences. In the assimilation model, however, problematic experiences are problematic from the perspective of the dominant community of voices - the client's usual self, which experiences pain when the problem emerges. Putting the models together, then, the problematic self-narrative in the innovative moments model is precisely what binds together the dominant community of voices in the assimilation model at the beginning of therapy (Osatuke et al., 2004; Stiles, 2011). Conversely, problematic experiences, in the assimilation model, are precisely the innovative voices that are excluded by initial self-narrative in the innovative moments model.

\section{References}

Angus, L., Levitt, H., \& Hardtke, K. (1999). The narrative process coding system: Research applications and implications for psychotherapy practice. Fournal of Clinical Psychology, 55, 1255-1270.

Angus, L., \& Greenberg, L. (2011). Working with narrative in Emotion-focused Therapy: Changing stories, healing lives. Washington DC: American Psychological Association Press.

Beck, A. T., Ward, C. H., Mendelson, M., Mock, J., \& Erbaugh, J. (1961). An inventory for measurement of depression. Archives of General Psychiatry, 4, 561-571. doi:10.1001/archpsyc.1961. 01710120031004

Bruner, J. (1990). Acts of meaning. Cambridge, MA: Harvard University Press.

Caro Gabalda, I. (1992). La terapia cognitiva de evaluación: Datos sobre su eficacia [Linguistic therapy of evaluation: Data on its efficacy]. Boletín de Psicología, 37, 80-109.

Caro Gabalda, I. (1996). The linguistic therapy of evaluation: A perspective on language in psychotherapy. Fournal of Cognitive Psychotherapy, 10, 83-104.

Caro Gabalda, I. (1997). El estado de la cuestión en la terapia lingüística de evaluación. [The state of the art of linguistic therapy of evaluation]. In I. Caro Gabalda (Ed.), Psicoterapias cognitivas: Estado de la cuestión y procesos terapéuticos [Cognitive psychotherapies: State of the art and therapeutic processes] (pp. 279-290). Barcelona: Paidós.

Caro Gabalda, I. (1999). La investigación de procesos: Análisis de tareas y cambio terapéutico en la terapia lingüistica de evaluación [Process research: Task analysis and therapeutic change in linguistic therapy of evaluation]. Special Issue. Psicologemas, 25-26, 1-192.

Caro Gabalda, I. (2006). The assimilation of problematic experiences in linguistic therapy of evaluation: How did María assimilate the experience of dizziness? Psychotherapy Research, 16, 422-435. doi:10.1080/10503300600756436

Caro Gabalda, I. (2007). La asimilación de experiencias problemáticas en la terapia lingüística de evaluación. ¿Cómo asimiló María su incapacidad para hacer cosas? [The assimilation of problematic experiences in linguistic therapy of evaluation. How did María assimilate her inability for doing things?] Boletín de Psicología, 89, 47-73.

Caro Gabalda, I. (2008). Assimilation of problematic experiences in linguistic therapy of evaluation: A case study. Fournal of Constructivist Psychology, 21, 151-172. doi:10.1080/1072053 0701853735

Caro Gabalda, I. (2009). Convergence of voices in linguistic therapy of evaluation. Clinical Psychology and Psychotherapy, 16, 182-198. doi:10.1002/cpp.614

Caro Gabalda, I., \& Stiles, W. B. (2009). Retrocesos no contexto de terapia linguística de avaliaçâo [Setbacks in the context of linguistic therapy of evaluation]. Análise Psicologica, 2(XXVII), 199-212.

Caro Gabalda, I., \& Stiles, W. B. (2013). Irregular assimilation progress: Setbacks in the context of linguistic therapy of evaluation. Psychotherapy Research, 1, 35-53.

Detert, N. B., Llewelyn, S., Hardy, G. E., Barkham, M., \& Stiles, W. B. (2006). Assimilation in good-and poor-outcome cases of very brief psychotherapy for mild depression: An initial comparison. Psychotherapy Research, 16, 393-407. doi:10.1080/ 10503300500294728

Dimaggio, G., \& Lysaker, P. H. (Eds.). (2010). Metacognition and severe adult mental disorders: From basic research to treatment. London: Routledge

Dimaggio, G., Salvatore, G., Azzara, C., \& Catania, D. (2003). Rewriting self-narratives: The therapeutic process. Fournal of Constructivist Psychology, 16, 155-181. doi:10.1080/107205303 90117920

Goldsmith, J. L., Mosher, J. K., Stiles, W. B., \& Greenberg, L. S. (2008). Speaking with the client's voice: How a personcentered therapist used reflections to facilitate assimilation. 
Person-centered and Experiential Psychotherapies, 7, 155-172. doi:10.1080/14779757.2008.9688462

Gonçalves, M. M., Cruz, G., Mendes, I., Ribeiro, A., Sousa, I., Angus, L., \& Greenberg, L. (2012). Innovative moments and change in client centered therapy. Psychotherapy Research, 22, 389-401. doi:10.1080/10503307.2012.662605

Gonçalves, M. M., Matos, M., \& Santos, A. (2009). Narrative therapies and the nature of "unique outcomes" in the construction of change. Fournal of Constructivist Psychology, 22, 1-23. doi:10.1080/10720530802500748

Gonçalves, M. M., Matos, M., Salgado, J., Santos, A., Mendes, I., Ribeiro, A., Cunha, C., \& Gonçalves, J. (2010). Innovations in psychotherapy: Tracking the narrative construction of change. In J. D. Raskin, S. K. Bridges, \& R. Neimeyer (Eds.), Studies in meaning 4: Constructivist perspectives on theory, practice, and social justice (pp. 27-62) New York: Pace University Press.

Gonçalves, M. M., Mendes, I., Ribeiro, A., Angus, L., \& Greenberg, L. (2010). Innovative moments and change in emotion-focused therapy: The case of Lisa. Fournal of Constructivist Psychology, 23, 267-294. doi:10.1080/10720537.2010.489758

Gonçalves, M. M., Ribeiro, P. A., Mendes, I., Matos, M., \& Santos, A. (2011). Tracking novelties in psychotherapy process research: The innovative moments coding system. Psychotherapy Research, 21, 497-509. doi:10.1080/10503307.2011.560207

Gonçalves, M. M., \& Ribeiro, A. P. (2012). Narrative processes of innovation and stability within the dialogical self. In H. J. M. Hermans \& T. Gieser (Eds.), Handbook of dialogical self (pp. 301-318). Cambridge: Cambridge University Press.

Hermans, H. J. M. (2003). The construction and reconstruction of a dialogical self. Fournal of Constructivist Psychology, 16, 89-130. doi:10.1080/10720530390117902

Hermans, H. J. M., \& Kempen, H. J. G. (1993). The dialogical self: Meaning as movement. San Diego, CA: Academic Press.

Hermans, H. J. M., \& Hermans-Konopka, A. (2010). Dialogical self theory. Positioning and Counter-Positioning in a Globalizing Society. Cambridge: Cambridge University Press.

Hermans, H. J. M., Kempen, H. J. G., \& van Loon, R. P. J. (1992). The dialogical self: Beyond individualism and rationalism. American Psychologist, 47, 23-33. doi:10.1037/0003066X.47.1.23

Honos-Webb, L., \& Stiles, W. B. (1998). Reformulation of assimilation analysis in terms of voices. Psychotherapy, 35, 2333. doi: $10.1037 / \mathrm{h} 0087682$

Honos-Webb, L., Stiles, W. B., Greenberg, L. S., \& Goldman, R. (1998). Assimilation analysis of process-experiential psychotherapy: A comparison of two cases. Psychotherapy Research, $8,264-286$.

Honos-Webb, L., Surko, M., \& Stiles, W. B. (1998). Manual for rating assimilation in psychotherapy. Unpublished manuscript. Miami University, Ohio.

Honos-Webb, L., Surko, M., Stiles, W. B., \& Greenberg, L. S. (1999). Assimilation of voices in psychotherapy: The case of Jan. Fournal of Counseling Psychology, 46, 448-460. doi:10.1037/ 0022-0167.46.4.448

Knobloch, L. M., Endres, L. M., Stiles, W. B., \& Silberschatz, G. (2001). Convergence and divergence of themes in successful psychotherapy: An assimilation analysis. Psychotherapy, 38, 3139. doi:10.1037/0033-3204.38.1.31

Korzybski, A. (1933). Science and sanity. Lakeville, CT: Institute of General Semantics.

Korzybski, A. (1951). The role of language in the perceptual processes. In R. R. Blake \& V. Ramsey (Eds.), Perception: An approach to personality (pp. 170-205). New York: The Ronald Press.

Lani, J. A., Glick, M. J., Osatuke, K., Brandenburg, C., Gray, M. A., Humphreys, C. M., Reynolds, D., \& Stiles, W. B. (2002). Markers of assimilation manual. Unpublished manuscript. University of Ohio.
Leiman, M., \& Stiles, W. B. (2001). Dialogical sequence analysis and the zone of proximal development as conceptual enhancements to the assimilation model: The case of Jan revisited. Psychotherapy Research, 11, 311-330. doi:10.1080/713663986

Matos, M., Santos, A., Gonçalves, M. M., \& Martins, C. (2009). Innovative moments and change in narrative therapy. Psychotherapy Research, 19, 68-80. doi:10.1080/10503300802430657

Mendes, I., Ribeiro, A. P., Angus, L. E., Greenberg, L. S., \& Gonçalves, M. M. (2010). Narrative change in emotionfocused therapy: How is change constructed through the lens of the Innovative Moments Coding System? Psychotherapy Research, 20, 692-701. doi:10.1080/10503307.2010.514960

Mergenthaler, E., \& Stinson, C. H. (1992). Psychotherapy transcription standards. Psychotherapy Research, 2, 125-142. doi:10.1080/10503309212331332904

Mosher, J. K., \& Stiles, W. B. (2009). Client's assimilation of experiences of their therapists. Psychotherapy: Theory, Research, Practice E Training, 46, 432-447. doi:10.1037/a0017955

Osatuke, K., Glick, M. J., Gray, M. A., Reynolds, D. J., Jr., Humphreys, C. L., Salvi, L. M., \& Stiles, W. B. (2004). Assimilation and narrative: Stories as meaning bridges. In L. Angus \& J. McLeod (Eds.), Handbook of narrative and psychotherapy: Practice, theory, and research (pp. 193-210). Thousand Oaks, CA: Sage.

Osatuke, K., Glick, M. J., Stiles, W. B., Greenberg, L. S., Shapiro, D. A., \& Barkham, M. (2005). Temporal patterns of improvement in client-centered therapy and cognitive-behaviour therapy. Counseling Psychology Quarterly, 18, 95-108. doi:10.1080/ 09515070500136900

Osatuke, K., Stiles, W. B., Barkham, M., Hardy, G. E., \& Shapiro, D. A. (2011). Relationship between mental states in depression: The assimilation model perspective. Psychiatry Research, 190, 52-59. doi:10.1016/j.psychres.2010.11.001

Ribeiro, A., Gonçalves, M. M., \& Ribeiro, E. (2009). Processos narrativos de mudança em psicoterapia: Um estudo de caso de sucesso de terapia constructivista. Psychologica, 50, 181-203.

Ribeiro, A. P., Bento, T., Salgado, J., Stiles, B., \& Gonçalves, M. M. (2011). A dynamic look at narrative change in psychotherapy: A case-study using the State-Space Grids. Psychotherapy Research, 21, 54-69. doi:10.1080/10503307.2010.504241

Ribeiro, E., Ribeiro, A. P., Gonçalves, M. M., Horvath, A. O., \& Stiles, W. B. (2013). How collaboration in therapy becomes therapeutic: The therapeutic collaboration coding system. Psychology and Psychotherapy: Theory, Research and Practice, 3, 294-314.

Sarbin, T. (Ed.). (1986). Narrative psychology: The storied nature of human conduct. New York: Praeger.

Spielberger, C. D., Gorsuch, R. L., \& Lushene, R. E. (1970). STAI, Manual for the State-Trait Anxiety Inventory (Self Evaluation Questionnaire). Mountain View, CA: Consulting Psychologists Press.

Stiles, W. B. (2002). Assimilation of problematic experiences. In J. C. Norcross (Ed.), Psychotherapy relationships that work (pp. 357-365). Cary, NC: Oxford University Press.

Stiles, W. B. (2005). Extending the Assimilation of Problematic Experiences Scale: Commentary on the special issue. Counseling Psychology Quarterly, 18, 85-94. doi:10.1080/ 09515070500136868

Stiles, W. B. (2006). Assimilation and the process of outcome: Introduction to a special section. Psychotherapy Research, 16, 389-392. doi:10.1080/10503300600735497

Stiles, W. B. (2011). Coming to terms. Psychotherapy Research, 21, 367-384. doi:10.1080/10503307.2011.582186

Stiles, W. B., \& Brinegar, M. (2007). Insight as a stage of assimilation: A theoretical perspective. In L. G. Castonguay \& C. E. Hill (Eds.), Insight in psychotherapy (pp. 101-118). Washington DC: APA. 


\section{M. M. Gonçalves et al.}

Stiles, W. B., Elliott, R., Llewelyn, S., Firth-Cozens, J., Margison, F. R., Shapiro, D. A., \& Hardy, G. (1990). Assimilation of problematic experiences by clients in psychotherapy. Psychotherapy, 27, 411-420. doi:10.1037/0033-3204.27.3.411

Stiles, W. B., Meshot, C. M., Anderson, T. M., \& Sloan, W. W. (1992). Assimilation of problematic experiences: The case of John Jones. Psychotherapy Research, 2, 81-101. doi:10.1080/ 10503309212331332874

Stiles, W. B., Morrison, L. A., Haw, S. K., Harper, H., Shapiro, D. A., \& Firth-Cozens, J. (1991). Longitudinal study of assimilation in exploratory psychotherapy. Psychotherapy, 28, 195-206. doi:10.1037/0033-3204.28.2.195
Stiles, W. B., Osatuke, K., Glick, M. J., \& Mackay, H. C. (2004). Encounters between internal voices generate emotion: An elaboration of the assimilation model. In H. H. Hermans \& G. Dimaggio (Eds.), The dialogical self in psychotherapy (pp. 91107). New York: Brunner-Routledge.

White, M. (2007). Maps of narrative practice. New York: Norton.

White, M., \& Epston, D. (1990). Narrative means to therapeutic ends. New York: Norton.

Zigmond, A. S., \& Snaith, R. P. (1983). The Hospital Anxiety and Depression Scale. Acta Psychiatrica Scandinavica, 67, 361-370. doi:10.1111/j.1600-0447.1983.tb09716.x

Appendix 1. Fine-grained comparison of IMs and APES coding

\begin{tabular}{|c|c|c|c|c|c|c|c|c|c|}
\hline & APES 0 & APES 1 & APES 2 & APES 3 & APES 4 & APES 5 & APES 6 & APES 7 & IMs without APES \\
\hline Action & 0 & 1 & 14 & 8 & 3 & 6 & 0 & 0 & 16 \\
\hline Reflection & 0 & 11 & 34 & 47 & 27 & 19 & 8 & 0 & 243 \\
\hline Protest & 0 & 3 & 2 & 5 & 4 & 2 & 3 & 0 & 22 \\
\hline Performing Change & 0 & 0 & 0 & 0 & 3 & 6 & 4 & 0 & 3 \\
\hline Reconceptualization & 0 & 0 & 0 & 0 & 1 & 3 & 2 & 0 & 3 \\
\hline APES without IMs & 0 & 7 & 101 & 76 & 27 & 4 & 0 & 0 & \\
\hline
\end{tabular}

Appendix 2. Examples of IMs and APES convergence and divergence

\begin{tabular}{|c|c|c|c|}
\hline & Passage & IM coding & APES coding \\
\hline \multirow[t]{2}{*}{ Low levels Divergence } & $\begin{array}{l}\text { C: I mean, in concrete situations, (Therapist (T): Mhm), I cope better } \\
\text { with them than with the uncertainty. (Of course. Sure.) I feel more } \\
\text { anxious when I am insecure about what is going to happen, or what } \\
\text { they will do, or how it will be, than when someone tells me: "This is it." } \\
\text { Because when we know what is going on, we cope with it. (T: Mhm). } \\
\text { Then, I am brave. I am a strong and determined person. (session 6) }\end{array}$ & Reflection & Absent \\
\hline & $\begin{array}{l}\text { C: (...) I recognise that... [worries] are not good for anything, because } \\
\text { there are some things that truly worry you, but they aren't actually... } \\
\text { they are not real worries... but to you they were because you were } \\
\text { thinking about them before. And there you were, worrying about } \\
\text { something that solves by itself, and you shouldn't have spent your time } \\
\text { planning and thinking, because it was solved normally, by itself. } \\
\text { (session 1) }\end{array}$ & Protest & Absent \\
\hline & $\begin{array}{l}\text { C: Yes, she [daugther] told me: “mum, don't worry because I can see } \\
\text { that you are happier and, even if you don't believe it, (T: Of } \\
\text { course...), you are doing more things than you did before, you don't } \\
\text { realize, but you are doing more than you did before.” It can be actually } \\
\text { truth, for example, before when I went out to go shopping and stuff like } \\
\text { that, I couldn't go alone, I couldn't... I felt like I was falling and it was } \\
\text { such a strong sensation, so strong that I came back home. Now it is } \\
\text { different, now I go outside everyday and I do everything that has to be } \\
\text { done... I go to her house, on the other side of the street, which is not far, } \\
\text { but I go twice or three times a day if it is necessary, and before... I } \\
\text { would never go. (session 12) }\end{array}$ & Performing Change & APES 4 \\
\hline
\end{tabular}

